\title{
The prevalence and impact of coffee arthropod pests in the gedeo indigenous agro forestry systems, Southern Ethiopia
}

\author{
Fekadu Gemechu*, Melesse Maryo and Girmaye Benti \\ Department of Biology, Dilla University College of Natural and Computational Sciences, P. O. Box - 419, Ethiopia.
}

Received 6 February, 2016; Accepted 26 July, 2016

\begin{abstract}
Coffee crop has been contributing a lion share to the Ethiopian economy. Despite of its economic significance, it suffers from many production constraints, of which arthropod pests influence both the yield and quality of coffee. The study was aimed to assess the prevalence of arthropod pests and indigenous management across two agro-climatic zones, in the Gedeo agroforestry systems. Twelve farmscapes were randomly selected from the two agro climatic zones. From each farmscape, samples were taken from traditional and improved coffee fields. On each site, two quadrats of $10 \mathrm{~m} \times 20 \mathrm{~m}$ plots of coffee fields were sampled to assess the presence/absence of pests and / or damage symptoms, the number of pest arthropods and the damage level per coffee tree for determining the pest prevalence. The number of pests per plant was subjected to SPSS ver.20 statistical software, and the pair wise comparison was computed to compare each study sites. The result indicates that the three top prevalent coffee pests were coffee berry borer $(H$. hampel), coffee white stem borer (A. leuconotus), and Serpentine leaf minor (C. alertreuta). However, there is no significant difference on pest prevalence among the agroclimatic zones. Although disease incidence was very high across the study sites, the highest incidence was recorded in Gololcha kebele (82\%), of Kochore district. In all cases the level of infestation was below standard, and coffee arthropod pests do not seem to be serious major problems responsible for the coffee production loss. Yet, we recommend multi seasonal and multi temporal data to arrive to the conclusion about the pest status of the study area.
\end{abstract}

Key words: Arthropod pests, coffee berry borer, damage level, farmscape, Gedeo.

\section{INTRODUCTION}

Coffee (Coffea arabica L.), which is thought to have originated in Ethiopia, is the backbone of the country's economy (Mesfin Ameha, 1991). Ethiopia contributes a total of 7 to $10 \%$ coffee induction to the world (FAO,
2010). In Ethiopia, about $20 \%$ of of the population depend on coffee for their livelihood which accounts for $35 \%$ of the total export earnings (Berhanu et al., 2013). About $70 \%$ of which is produced as garden coffee.

*Corresponding author. E-mail: gemechufekadu@gmail.com.

Author(s) agree that this article remains permanently open access under the terms of the Creative Commons Attribution License 4.0 International License 
Garden coffee is cultivated and produced in the homegardens of small-scale subsistence farmers, and is a low input-output crop in the southern and southeastern parts of the Ethiopia, with plots of varying size (usually < $0.5 \mathrm{ha})$ around farmers' dwellings and predominantly intercropped with a variety of fruit, root and cereal crops (Girma et al., 2008).

Although 103 species of Coffea and seven infraspecific taxa-have been recognized worldwide (Waller et al., 2007), only two are economically important. Coffee (Coffea arabica L. and C. canephora Pierre ex A. Froehner) is the world's most valuable tropical export crop, with an annual retail value of approximately US $\$ 90$ billion (ICO, 2011). C. arabica is preferred to coffee species due that it is taken as superior quality for its taste and organic nature (Fuad, 2010). Arabica coffee offers superior cup quality and aroma compared with Robusta, which commonly owns a more aggressive flavor and, in light roast coffee, has a flat popcorn-like aroma which is responsible for approximately $70 \%$ of the global coffee market. C. arabica prices have increased by $160 \%$ during the past years (ICO, 2011) that is related with production shortages, small farm size, lowest-ever world market prices due to increasing temperature and consequent damages, among other reasons (Jaramillo, 2011).

Coffee production is constrained by copious factors (both biotic and abiotic), including losses due to damage by pests and diseases, poor management practices, soil infertility, and poor pricing. Poor price of coffee is also associated with the damage caused by pests, particularly insects that are proliferated by the climate change. Thus, with the current climate change it seems rational to evaluate the status of insect pests meant to sustain the management of coffee plantation. The incidence and spread of pests and disease are also likely to increase and affect crop yields and quality. For instance, the proliferation of the coffee berry borer, the world's most important coffee pest, in East Africa and parts of South America is predicted to push arabica production to higher areas where the pest do not flourish (Jaramillo, 2011). Insect pests are among a number of factors that contribute to low yield. Greater than 45 insect pests were reported in coffee fields from Ethiopia (Million, 2000). Some insect pest species such as Antestia bugs, and coffee leaf miner, Leucoptera caffeina (Washbour) are considered as major insect pests of coffee particularly in larger farms. Coffee berry borer, Hypothenemus hampei (Ferriere) is a potentially important insect pest of coffee in Ethiopia (Girma Adugna, 2008). Losses due to coffee pests are estimated to be $13 \%$ worldwide (Nyambo and Masaba, 1997). The yield loss due to some insect pests such as Anthestia bug was reported to be $9 \%$ in Ethiopia (Girma, 2008).

Over the past 3 to 4 decades, changing climate, particularly global warming has already produced numerous shifts in the distribution and abundance of many species. Climate change and invasive species are considered as two of the most important ecological issues facing the world today (Ward and Masters, 2007). Drought and warm climate condition, and irregularity of rain were suggested as means to have caused pest outbreak in Gedeo agroforestry (Abdu and Tewodros, 2013). The changes in climatic conditions are predicted to profoundly influence the population dynamics and the status of agricultural insect pests and as temperature has a strong and direct influence on insect development, reproduction and survival (Ward and Masters, 2007). The impact of insect pest problem is pronounced more in intensive coffee production system than coffee in traditional home gardens and semi forest coffee since such systems could have long traditional and culturally associated protection practices (Million, 1987).

Furthermore, a study from Sidama, Ethiopia showed that less susceptible to disease and insect pests, better economic and market related issues, growth under broad climatic conditions, tolerance to drought for long periods caused farmers to prefer khat to coffee cultivation (Gessesse, 2007). Gedeo Zone is one of the major coffee growing areas at altitudinal range of 1500 to $1800 \mathrm{~m}$ asl, which requires special attention for its peculiar floral quality of the agroforestry system (FAO, 1998). The organic coffee is grown under shade that covers $47 \%$ of the total land in Gedeo that supports more than one million of the people (GRADAO, 2010). However, the status of coffee production with respect to insect pests in Gedeo agro forestry is not well known. Thus, this research seeks to find methods to manage insect pests and related disease, improve coffeee production among smallhodler farmers and sustain productivity; the type of insect pests need to be identified and management option has to be forwarded, among other factors. The current study was aimed to assess the diversity of existing arthropods and other pests, and to examine the level of damage among coffee landraces across different agroclimatic zones.

The general objective of the study was to assess the prevalence of arthropod pests and others, their management across agro-climatic zones, in Gedeo agro forestry system, SNNPR, Ethiopia whereas the specific objectives of this study were to assess for the diversity of existing arthropods and other pests on coffee plant in Gedeo agro forestry system; to identify the level of damage between varieties and land races in relation to pests' population and their indigenous management options, and to estimate the implication of the influence that pests could cause on the production and productivity of the coffee in Gedeo zone.

\section{Description of the study area}

The Gedeo Zone with a total area of $1,347 \mathrm{~km}^{2}$ and an altitude range of 1,350 to $3,000 \mathrm{~m}$ asl, stretches along the main highway from Addis Ababa to Moyale (located 


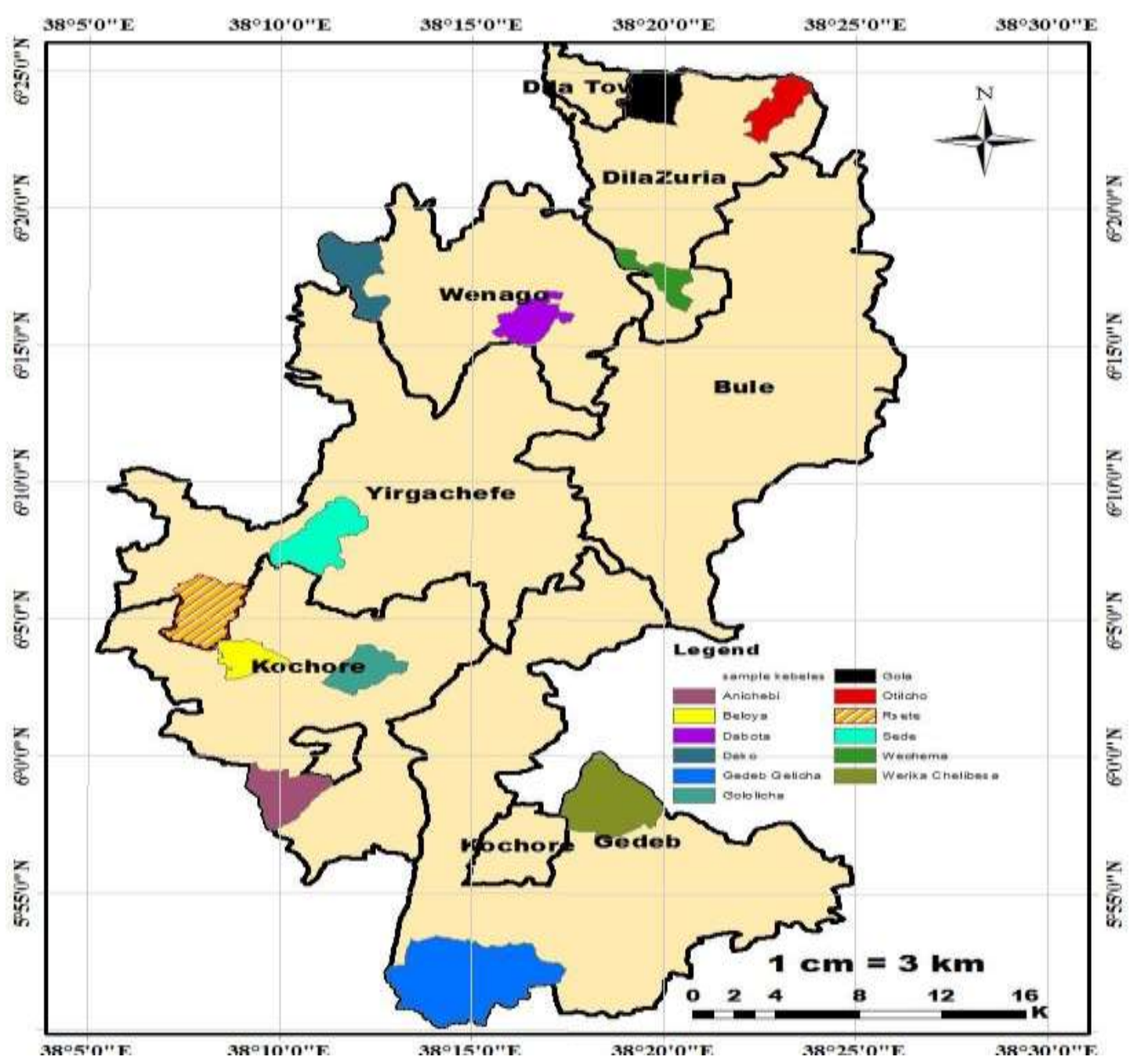

Figure 1. Map of the Gedeo zone, Southern Ethiopia.

about $360 \mathrm{~km}$ away from Addis Ababa or $85 \mathrm{~km}$ away from the Regional Capital, Hawassa). The study area includes all the coffee growing farmscapes of Gedeo Zone, Ethiopia (GZARD, 2015). Agroecologically, Gedeo Zone covers $70 \%$ Woina Dega/mid altitude that ranges from 1800 to $3200 \mathrm{~m}$ asl, 28\% Dega (high land, 2400 to $3200 \mathrm{~m}$ asl), and $2 \%$ kola (lowlands, 500 to $1800 \mathrm{~m}$ asl,) (Daniel, 1977). Figure 1 indicates the map of sample kebeles (lower administrative units). Geographically, the Zone is located North of Equator from $5^{\circ} 53^{\prime} \mathrm{N}$ to $6^{\circ} 27^{\prime} \mathrm{N}$ latitude and from $38^{\circ} 8^{\prime}$ to $38^{\circ} 30^{\prime}$ 'East,longitude (Figure 1).

\section{METHODS}

The approach for this study involved mixed qualitative and quantitative methods. The study was carried out in a three-stage process as follows: The first stage involved designing the methodology and piloting of zonal mapping of the coffee producing areas. The mapping was designed to identify key agents and stakeholders and to develop hypotheses for carrying out the household survey. The second stage involved conducting the household and field survey on coffee producing areas. Finally, the third stage involved gathering information from a meeting with key informants to pinpoint on the specific problems and the existing pests and their status.

\section{Source of data}

The study was conducted to collect data only from primary sources (original data collection) and the other is a review of existing literature. Quantitative data were collected from 180 households and nearly 50 in-depth key informant interviews from May 2014 to October 2014, with the objective of uncovering interests and incentives of various relevant actors to the sector. Samples for the households were drawn from representatives of coffee producers in their respective kebeles. The data collected include socio-economic aspects of the households, coffee landraces, constraints to coffee production, coffee pests and their effects, and indigenous management of coffee. 


\section{Data collection tools}

For data collection, both questionnaires and semi-structured interviews were arranged which was translated to the local language (Amharic and Gedeoffa) for the sake of clarity. In addition, direct observations of the coffee shrubs in the selected sites per kebele were done.

\section{Sample collection}

The five woredas were characterized by differences in type of coffee grown, holding size and method of cropping. At higher elevations, where disease incidence, and therefore, cost of production is higher, coffee has been neglected or uprooted to a far greater extent than in lower elevations. Twelve farmscapes from two main agroclimatic zones of coffee producing areas, namely Woyna, Dega and Kolla were randomly sampled. Farmscape is a landscape in which farming has largely performed and does play a large role. From each farmscape, two sites one from indigenous traditional coffee landraces and other from improved coffee landraces (Serto Masaya) were deliberately selected. Two quadrats of coffee field $(10 \mathrm{~m} \times 20 \mathrm{~m})$, each was sampled to assess the varieties of coffee (landraces), presence /absence of any sort of pests (arthropod) and / or damage symptom. The age of the sample coffee landraces used for the study was $\geq 5$ years. The target population for sampling was coffee growers rather than general pool of famers. The survey was used to benchmark yields reduction due pests and adoption of improved practices for assessing the impact.

The number of pest organisms, and/or damage per parts of the coffee plant was taken as parameters to determine the pest status or load was determined as major (1), potentially important (2), and minor pests (3) following (Esayas and Chemeda, 2007). Coffee landraces were examined for production and resistance to pest organisms. The observed pests were collected to plastic bags with some parts of the coffee plant to serve as a food for some times until the species identification. Then, the collected pests were identified using the identification keys in the Entomological Laboratory of Dilla University. One hundred eighty farm households were selected to gather data on the indigenous pest management using questionnaires. Furthermore, fifty key informants were interviewed to gather the data on indigenous knowledge of the pest management.

\section{Surveillance conducted}

The researchers conducted detection, delimiting and monitoring targeted places and parts, trackback and track forward, and sentinel site surveys, for any of the pests. The detection was conducted to determine whether the pest is prevalent in a defined area where it is not known to occur before. This was very broad in scope since the pest surveillance was done over large areas to examine the coffee damage, and symptoms by the suspected pest species on the seed, leaf, stem and root areas. Statistically, a detection survey is not a valid tool to claim that a pest does not exist in an area even if the results are negative. Negative results can be used to provide clues about the mode of dispersal, temporal occurrence, etc. Negative results are also important to compare results with sites that are topographically, spatially, or geographically similar (Roger and Wilson, 2009).

\section{Survey procedures}

The following tools were used singly or in any combination to detect the presence of insect pests and others. Coffee shrubs were of other potential host plants, and nearby resting places for adults.

Disturbing plants to provoke the flight of adults and collection of samples of insects while inspecting potential host plants or plant part is a must. High risk areas where the pest is more likely to be found was focused on and regular sites were established to inspect along the normal surveying route following Roger and Wilson (2009).

Since pests are found attacking nursery stock, surveyors compiled list of facilities associated with the nursery stock infested with pests. Sweep-net and areal nets were used to collect adult samples. Therefore, for all the surveillance roving survey was employed to assess pest population and the damage they inflict following Pedigo and Rice (2006). The relative measure of insect damage was determined as follows: The damage status was considered as:

1. Low if pest population is one to two per coffee plant

2. Moderate if population is three to five per coffee plant

3. High if population is five insect per plant, and

4. Severe if it is above five.

\section{Identification of farmers' indigenous management practices}

Semi-structured interview was used to collect data on coffee production, challenges and indigenous pest management practices. Questions were directed to provide an indication of farmers' perceptions and knowledge, decision-making indicators related to pest management strategies. The economic injury level (EIL) is the method used to determine when an insect (or any other organism) becomes a "pest," so that management (ecological or otherwise) needs to be undertaken for the simplified way of illustrating when an insect becomes a pest as stated by Rechcigl and Rechcigl (2000). The most frequently used equation to determine the economic injury level (EIL) is:

$\mathrm{EIL}=C \div \operatorname{VIDK}$

Where: $C=$ management costs per production unit (e.g. $\$ /$ ha), $V=$ market value per production unit $(\$ / \mathrm{kg}), \quad I=$ injury per pest equivalent, $D=$ damage per unit injury (kg reduction/ha/injury unit) and $K=$ proportional reduction in injury with management (Pedigo et al., 1986).

For practical field use, the economic threshold (ET) is generally recommended which is the pest density at which control action should be taken to prevent the pest population from reaching or exceeding the EIL (Pedigo and Rice, 2006). During the assessment for the prevalence of disease in the area; the disease incidence formula was employed using:

Disease Indidence $=\frac{\text { Number of Infected Coffee }}{\text { Total Number of Coffere Tree }}+100$

Data analysis

Different methods of data analysis have been employed in this study depending on type of data and the methods of collection. Both descriptive and inferential statistical methods were used. SPSS Ver. 20 was used to compute ANOVA $(P<0.05)$.

\section{RESULTS}

\section{Background of the informants}

Seventy percent of the informants were males, and the 


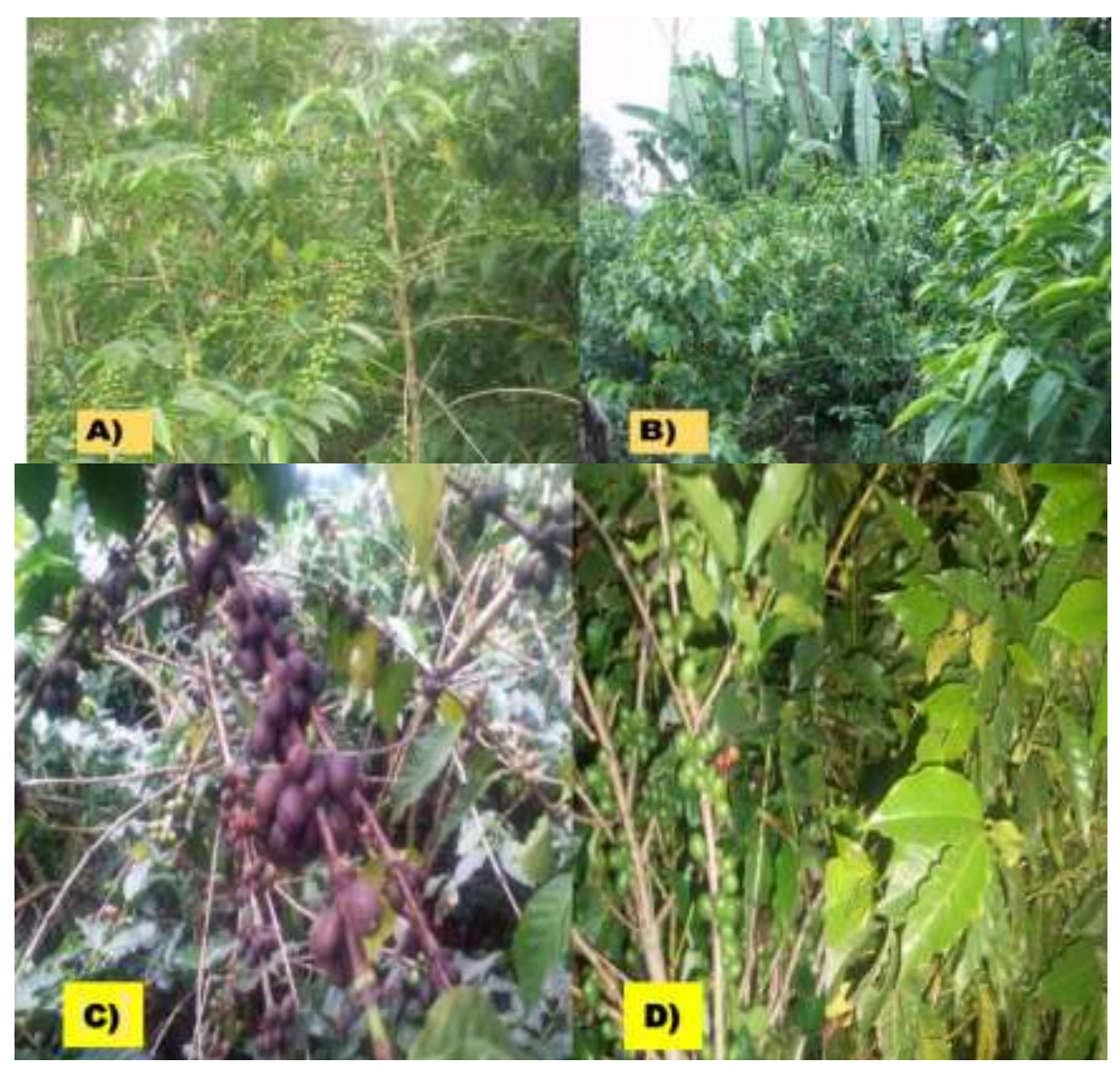

Figure 2. Some of the coffee landraces: (A) Serto, (B) Wolisho (C) Dega and (D) Wolisho infected.

average age of the informants was 47 years with a range of 35 to 92 showing that the informants had long experience of growing coffee crop. About $85 \%$ of the informants were able to read and write (average grade level, $6.2 \pm 2.4$, mean $\pm S D$ ), which also indicates the fertile ground that someone can transfer an appropriate adoption technology for the improvement of coffee production. The studied households $(\mathrm{HHs})$ with the mean family size and labor force of $8 \pm 2.1$ and $4 \pm 1.3$, respectively shows the presence of adequate human capital to grow and manage coffee field. The study population had an average land size of 0.53 ha and only $11 \%$ of them had off-faring activities, mainly trading. The annual mean income of the households was $5874 \pm 530$ (Ethiopian Birr), which is lower than the annual mean income of the country (currently > 10000 birr). These figures show the higher density of coffee farming households with limited resource availability could decline the production quality as well as the quantity of coffee crop.

\section{Coffee landraces and the ecosystem services}

The current study has identified four main coffee landraces under arabica coffee, based on some morphological characters (e.g., ripen berry color, berry size, flavor/taste, productivity, resistance to drought and /or disease), leaf size and apical leaf color) as well as informants confirmation. Of the common landraces recognized, the first three are locally accepted accessions, namely Kurumie (compact with small leaves and small sized berry), Wolisho (large leaves and bigger berry), Serto (improved variety named after the Amharic name 'Serto Masaya' to mean certified for demonstration to the users), and Deiga (the intermediate between Kurumie and Wolisho) (Figure 2).

There are many certified varieties (serto types) distributed from Ethiopian Agricultural Research Institutes. The following are among the improved varieties which are popular and currently being used by local farmers like 94110, 74112, 74158, 741 and 744. Kurmie and Wolisho are old farmer varieties, which hold the largest proportion while the improved variety types were not grown commonly by all households because they were more recently introduced by District Agricultural Office against diseases such as coffee berry disease which is endemic to east Africa (Figure 2D). According to informants, all the landraces were almost equally subjected to ecosystem disservices except pathogens. Fungal pathogens (not 


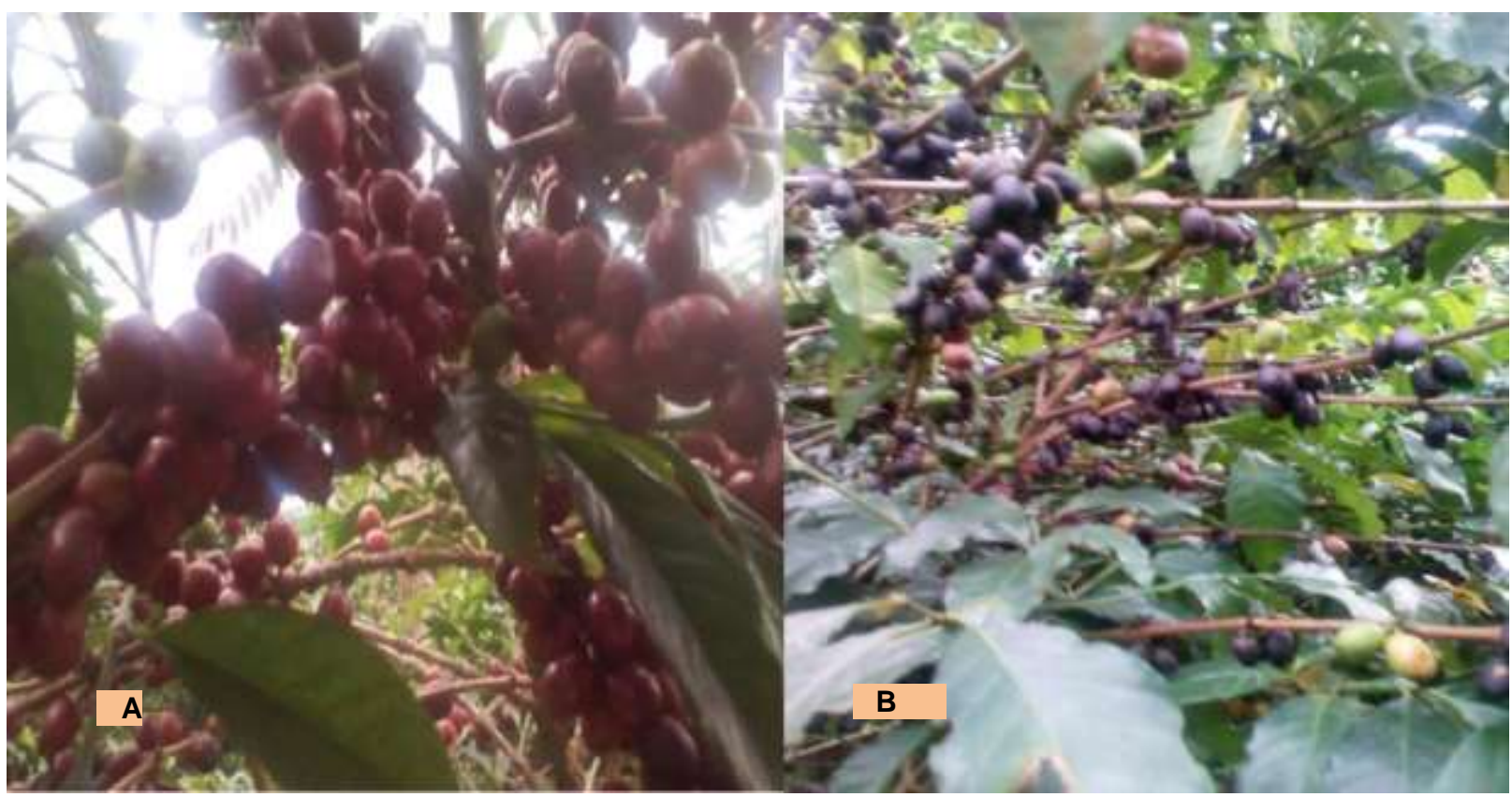

Figure 3. Land races: (A) Serto; (B) Wolisho.

covered in this study), mainly the coffee berry disease caused by Colletotrichum kahawae affected Wolisho variety more than Kurumie $>$ Diega $>$ Serto (Figure 3). The ecosystem disservices are the conditions and processes through which natural ecosystems and species reduce productivity or increase production costs. Crop pests investigated in the current study include herbivores, frugivores (fruit eaters), seed-eaters, and pathogens (e.g., fungal), which act as agents of ecosystem disserves.

The local people of Gedeo Zone reported that the ecosystem disservices are caused by Choroqa (mealy bug) which is the pest on the coffee root, Hanjame (green snake) which sucks coffee berry juice on aerial parts of coffee shrub, Gindi adrik (coffee white stem borer), cia, (birds) and rats (lema'e), and other vertebrates like monkeys and baboon. These organisms affect coffee production quality/quantity in different ways. Furthermore, parasitic plants like dodder, Loranthus, and other epiphytic plants like mosses and ferns were found on older coffee shrub branches. These species were found decreasing the quality of coffee productivity (Figure 4).

\section{Pests recorded}

During field survey in Gedeo indigenous agroforestry system, the insect pests most frequently encountered in all the selected localities are clearly identified and listed in Table 1. A lot of insects were observed on the green coffee berry and the damage caused was estimated by collecting sample injured and damaged coffee berry, leaves and branches. The pest status was calculated based on their load per coffee tree (Table 1) and the estimated damage pests inflict is depicted in Figure 5.

The major pests of coffee include boring beetles, scale insects, mealy bugs, other Hemiptera including anthestia, Lepidopterous miners and defoliators, nematode worms, mites weeds and others like slugs, snails, birds and mammals. Every part of the coffee shrub, that is, roots, stems, leaves, flowers, berries and the seed in storage can be attacked by insects and other pests in coffee growing areas.

The result indicated that there was statistically insignificant difference in the damage of coffee plant by various pests $(P>0.05)$. However, the highest, severe level was recorded by coffee berry borer, Hypothenemus hampei which is the world's worst coffee pest (Figure 5). Other arthropods and nematode worm populations were found to be below economic injury level, that is, the damage that this organism caused on coffee plant was insignificant (Figure 5). Nonetheless, the relative damage of major insects was the least on improved varieties (Serto) than local variety called Kurmie (Table 2). All the arthropod pests and others observed on the coffee shrubs were recorded and compared among and between the sampled sites (Figure 6). There was no significant difference among sites $(P>0.05)$. However, coffee berry borer and nematode worms revealed significant difference in terms of disease severity among the average number of observed pests $(P<0.05)$.

The damage measured differs from species to species. For instance, the damage caused by coffee berry borer and coffee white stem borer outweighs the other pests as 
Table 1. The list of insect pests of coffee recorded in Gedeo zone, Ethiopia.

\begin{tabular}{lllc}
\hline Scientific name & Common name & Family & Pest status \\
\hline Antestiopsis sp. & Anthestia bug & Pentatomidae & 1 \\
Anthores leuconotus Pascoe & White coffee borer & Cerambycidae & 1 \\
Archips occidentalis Wals. & Green tortrix & tortricidae & 3 \\
Ceroplastes brevicauda Hall & White waxy scale & Coccidae & 2 \\
Ceratitis capitata Wiedemann & Mediteranian fruit fly & Tephritidae & 3 \\
Coccus alpines De Lotto & Green scale & Coccidae & 2 \\
Cryphiomystis alertreuta Meyric & Serpentine leaf minor & Gracillaridae & 3 \\
Diarthrothrips coffeae Willams & Coffee thrips & Thripidae & 2 \\
Hypothenemus hampei Ferriere & Coffee berry borer & Scolytidae & 2 \\
Leucoplema dohertyi Warren & Coffee leaf skeletenizer & Epiplemidae & 3 \\
Leucoplema caffeine Washboum & Coffee bloch minor & Lyonetiidae & 1 \\
Stictococcus formicarius Newstead & Coffee cushion scale & Stictococcidae & 2 \\
Toxoptera aurantii Boyer & Coffee aphid & Aphididae & 3 \\
\hline
\end{tabular}

*Status: 1, major; 2, potentially important; 3 , minor pest; if (1-2 insect/plant) - low, if (3-5 insect/plant) - moderate, 5 - high and if ( $>5$ insect/plant) - severe in damage.

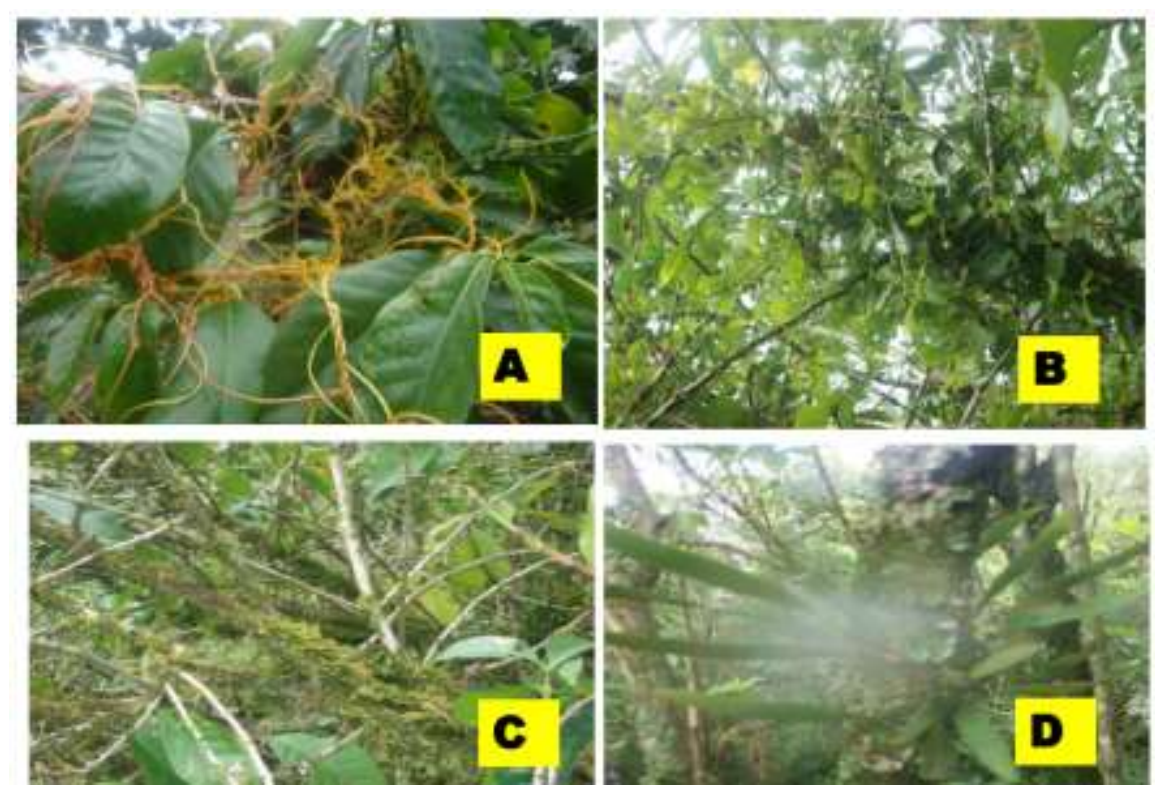

Figure 4. Parasitic and epiphytic plant species growing on coffee shrub decresasing its quality : A/ parasitic dodder ( Cuscuta $s p$ ) , B/ parasitic Loranthus species, C/ mosses $\mathrm{sp}$, and D/ Fern species

a single insect can lead the whole branch die back or leads to the level of drying to the whole tree (Table 2).

\section{Indigenous coffee field management}

Almost all the studied households grow the agroforestry tree species such as Albizia tanganica, Cordia africana, Erythrina abyssinica, and Millettia ferruginea, which are found to augment coffee yield since many of the trees fix nitrogen and possess large biomass that increases soil fertility. However, pruning coffee shrubs was found practiced by less than $50 \%$ of the study households that may increase the transfer of pests and reduce coffee productivity. About $35 \%$ of the sample households failed to prune agroforestry tree species which harbored some coffee diseases such as Coffee berry disease.

Most local people practiced regular picking to control some pests such as coffee berry borer. For the commonly identified pest organisms like Choroqa (mealy 


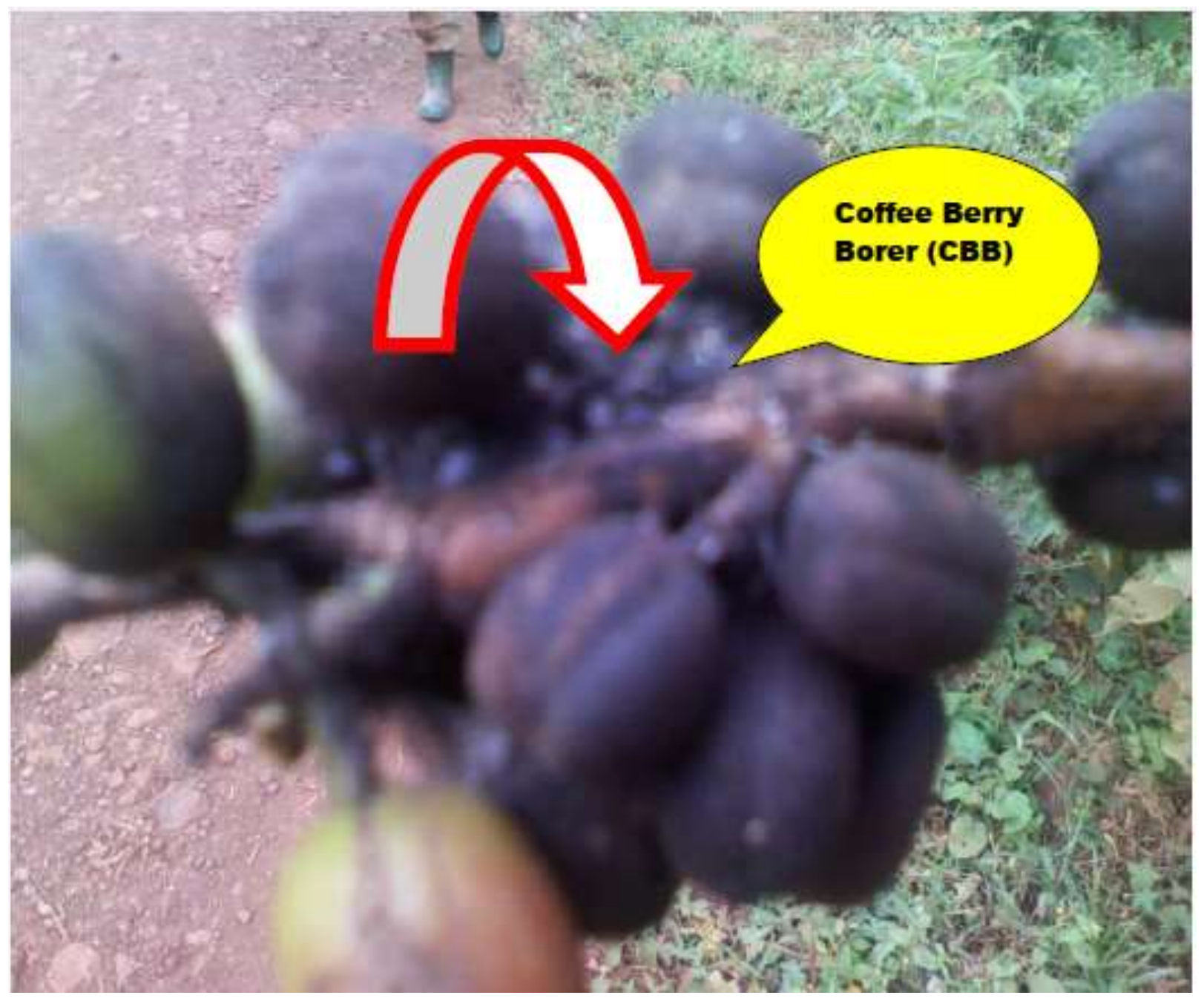

Figure 5. The load of coffee berry borer on coffee berries.

Table 2. The relative damage of major insects on coffee recorded per selected kebeles

\begin{tabular}{lllllll}
\hline \multirow{2}{*}{ Woredas } & \multirow{2}{*}{ Kebeles } & \multicolumn{2}{l}{ Common Land races of coffee Improved variety } & Major insect pests \\
\cline { 3 - 7 } & Kurmie & Welisho & Deiga & Serto & (CBB, CLM, CBM, CWSB) \\
\hline \multirow{2}{*}{ Konago } & Deko & Moderate & High & Severe & Moderate & CLM,CBB,CBM \\
& Dobota & Moderate & High & Severe & Low-moderate & CLM,CBB,CBM \\
& Golocha & low & High & Severe & Low & CLM,CBB,CBM \\
& Biloya & Moderate & High & Severe & Moderate & CLM,CBB,CBM \\
& Anchabi & Moderate & Severe & Severe & Moderate & CBB, CLM, CBM \\
\multirow{2}{*}{ Yirgachefe } & Sede & low & High & High & Low & CBB, CWSB \\
& Resite & Moderate & High & Moderate & Low & CBB \\
\multirow{2}{*}{ Dilla zuria } & Gola & Moderate & High & Severe & Moderate & CBB, CWSB \\
& Wachema & Moderate & High & Severe & Low & CBB, CBM \\
& Otilcho & Moderate & Severe & Severe & Moderate & CBB, CBM \\
\multirow{2}{*}{ Gedeb } & G/Galcha & Moderate & High & High & Low & CBM \\
\hline
\end{tabular}

${ }^{\star} \mathrm{CBB}$, coffee berry borer; CBM, coffee bloch minor; CLM, coffee leaf minor; CWSB, coffee white stem borer. 


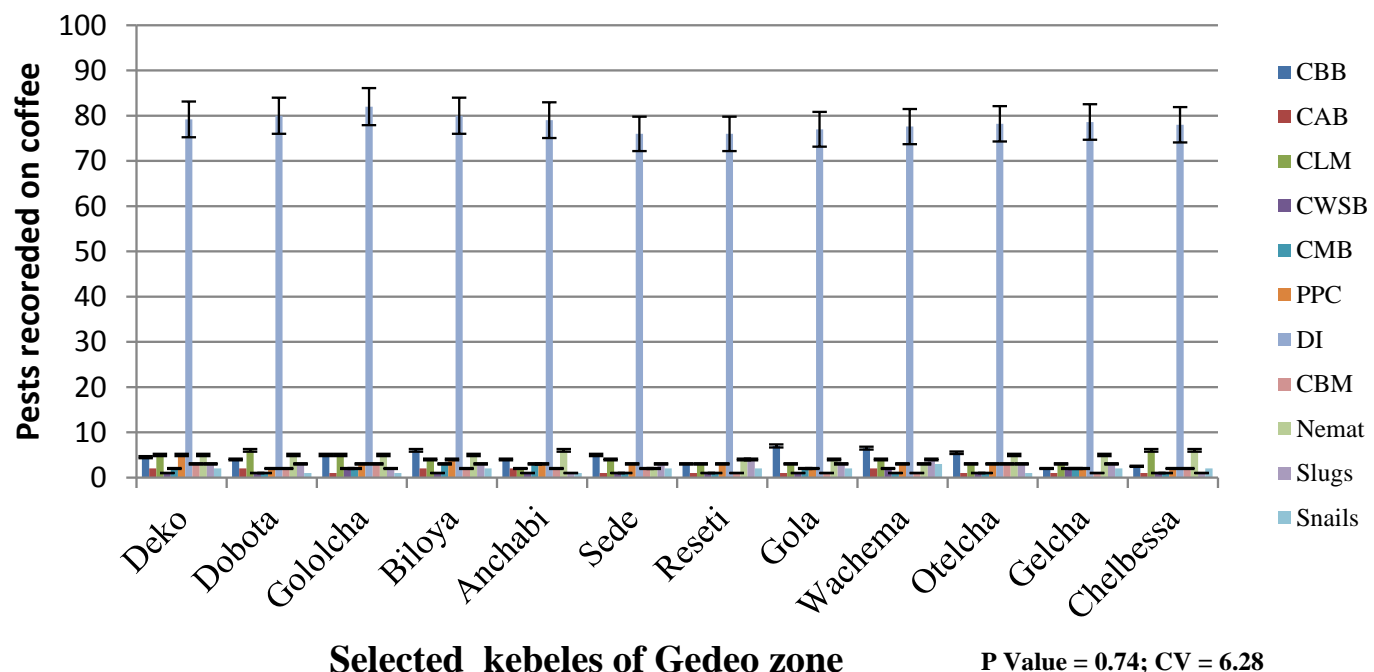

Figure 6. Pest diversity per kebeles of Gedeo zone. CBB, Coffee berry borer, CAB, coffee anthestia bug; CLM, coffee leaf miner; CWSB, coffee white stem borer; CMB, coffee mealy bug; PPC, plant parasitic on coffee; DI, disease incidence; CBM, coffee leaf bloch miner; Nemat, nematode worms in root.

bug), coffee sap sucking green snake (Hanjame), Gindi adrik (coffee white stem borer), and other vertebrates like monkeys and baboon, birds (cia), rats (lema'e) and thief (robbers) were informed as challenges, and were managed through going over on the farm.

\section{DISCUSSION}

\section{The diversity of insect pests and the damage level}

The current study investigated thirteen arthropod coffee pests in Gedeo enset- coffee based agroforestry system but Chemeda et al (2015) identified 12 insect families of five insect orders from afromontane rainforests in Southwestern Ethiopia where $C$. arabica L. has originated. There was no statistically significant difference in the damage of coffee plant by various pests $(P>0.05)$ among studied coffee landraces and across the study sites though the highest severity level was recorded by coffee berry borer, $H$. hampei, which is the world's worst coffee pest. Nonetheless, Chemeda et al. (2015) reported significance differences in insect pest occurrence between and within forest coffee populations with regard to coffee leaf damaging insects. The following are important classes of pests addressed in the Gedeo Zone.

\section{Major pests}

In the present study, coffee anthestia bug was found sucking green coffee berries, flower buds and growing tips. It was reported that after sucking berries, it finally blackens the flowers, flower buds, and causes fall of immature berries, and shortening of internodes. Similarly, coffee bloch leaf minor was found to cause severe defoliation coffee plant. However, Esayas and Chemeda (2007) reported that it never causes considerably yield loss.

\section{Potentially important insect pests}

Coffee berry borer was found the leading pest examined in the current study. It was first reported in 1968 by Davidson in Ethiopia and is currently the leading incidence being reported from different parts of the country (Mendesil et al., 2003). Coffee berry borer was seen attacking the green, ripe and dry berries in contrast to the previous investigation in Ethiopia (Million, 2000). Loss due to coffee berry borer inflict up to $60 \%$ damage on dry left over coffee berries in Ethiopia. Climate change particularly the raise in temperature in coffee growing areas has aggravated the problem by creating an environment conducive to the rapid growth of the pest Abdu (Abdu and Tewodros, 2013). The current study identified the black scale and coffee cushion scale causing low level of infestation. Regarding coffee scale insects, seven species were recorded in Ethiopia (Million, 2000). Similarly, the current study found that coffee thrips were seen feeding on leaves and green berries which is similar to the previous investigation by Esayas and Chemeda (2007). This may lead to coffee yeild reduction. However, further investigation on the impact on coffee productivity is required.

\section{Minor insect pests}

Serpentine leaf miner, coffee leaf skeletenizer, coffee 
aphids and fruit flies were among the most common insects observed. Serpentine leaf miner was very common affecting young leaf which outbreaks every year after the onset of short rain. The larvae of coffee leaf skeletenizer were feeding on the underside of leaf usually near mid rib eating everything except veins and upper epidermis leaving irregular lace-like patches. The other minor insect pests were coffee aphids, black soft bodied found in cluster on tips of (soft shoots, flower, flower buds and leaf), causing no direct damage but, can cause premature fall of young green berries. Similar results were reported by Esayas and Chemeda (2007).

\section{Indigenous pest management practices}

Various traditional management practices were recognized in Gedeo agroforestry system. For instance, coffee leaf miner, Leucoptera coffeina is often seen in shaded coffee causing minor impact, but considered as major pest by the growers in the study area. They manage density and canopy of the shade trees and then the number decreases significantly. Coffee berry borer is traditionally controlled by regular picking, take off and burning old and dry cherries while pruning keeps the canopy more open, less humid and unattractive to the pests such as Choroqa (mealy bug), and Gindi adrik (coffee white stem borer).

There are also a lot of techniques that are being used by the coffee growers for the management of pests in Gedeo zone, Southern Ethiopia. For instance, for the prevention of mealy bugs, growers apply adequate nutrition to a coffee plant in the form of fertilizer, mulch or well-rotted manure, and regular inspection and monitoring of on farm before the harvest of coffee berry. Moreover, they grow nitrogen fixing agroforestry trees such as Erythrina abyssinica and Millettia ferruginea to promote soil fertility and enhance coffee pest and disease protection. Similar practices were reported by Girma (2008). In some cases high density and large canopy shade trees were found to harbor pests such as coffee berry borer. Similar finding was reported by Van Der Vossen (2005). Additionally, failure to manage the old coffee shrubs has resulted in the expansion of epiphytic plants and other parasitic epiphytes to grow on coffee shrub which result in reduced coffee productivity. This requires adequate training and dissemination, particularly the extension workers should promote not only provision of improved crops but also protection of crops from disease and pests. Furthermore, advanced integrated pest management techniques should be operated as coffee is the major crop in the sampled area.

Fortunately, the well-managed coffee farm in Gedeo agroforestry system was less likely damaged by arthropod pests in general. For instance, coffee leaf minor, $L$. coffeina is below threshold level in shaded coffee and so have minor impact. The damage caused by coffee berry borer, $H$. hampei was less than $10 \%$ in the study farm sites. The Gedeo indigenous agro forestry system by itself is well managed and does not create conducive environment for pest outbreak, that is, acts as a physical barrier. The exposed coffee trees are evidence for this, since they are more attacked by pests compared to coffee trees found under shades. This could be associated with the presence of diverse natural enemies, which will keep the population at low level as described by Girma (2008). As a result, the agroforestry system is well suited for the diversity of pests and their natural density maintained below economic injury level. This is one of the components of IPM and need to be conserved for its sustainability.

\section{CONCLUSION AND RECOMMENDATIONS}

Four different coffee landraces were examined from Gedeo agroforestry system. Similarly, thirteen arthropod pests and five non arthropod vertebrate pest species were found to depend on coffee regardless of the landrace type. To recap, low damage level was examined by insect pests from the present study area regardless of the coffee landrace types. There were relatively insignificant insect pest problems in Gedeo indigenous agroforestry system as compared to coffee diseases that is caused by fungal /bacterial pathogenic agents, which could be associated with the presence of genetically diverse C. arabica as well as the existence of diverse natural enemies in complex agroforestry system of Gedeo Zone, that may keep the population of pests at low level. Gedeo indigenous agro forestry system contributes great in hosting diversity insects and natural enemies and have great role in an IPM strategy and need to be further studied for biological control.

The denser the canopy, the higher the probability of coffee infection was resulted. Among the four coffee landraces examined in this study, kurmie was preferred by $75 \%$ of the growers due to its better resistance to pests and disease.

Insects contribute much in vectoring pathogenic microbial infections. Other parasitic epiphytic plants (mosses, ferns and lichens), Dodder and Loranthus species were also found another challenge and needs cautious removal. The infected plant parts were dumped around the field (farm land) which acts as the inoculum for further infection. Since the growers are not properly coordinated and guided by the professionals, they are not managing their coffee plantations well in almost all sites, and they need to follow the wider spacing and pruning, making less dense canopy, use of resistant varieties and avoiding frequent replacement of seedlings per uprooted wilted trees. Thus, appropriate training should be given to relevant coffee farmers.

The knowledge gap among farmers in coffee management like spacing, removal of infected coffee, 
shade trees treatment, conserving biocontrol agents, using resistant variety, consulting professionals and implementation, disease prevention, shade and environmental management were among the major problems in the study area.

\section{Future trend in coffee production}

There were some limitations in this study, mainly the absence of continuous monitoring for the prevalence of insect pests and their temporal variation. Implementation of IPM should be taken as the first option in the future through coffee tree/canopy tree management, that is, minimizing the shade level, proper spacing, removal of infected and old plants, coffee field rotating, using resistant varieties and looking for improved varieties.

\section{Conflict of Interests}

The authors have not declared any conflict of interests.

\section{ACKNOWLEDGMENTS}

The authors are grateful to Dilla University Research and Dissemination Office for the grant of the research fund. They also thank Gedeo Zonal and Woreda Agriculture and Rural Development Offices, as well as coffee farmers and development agents of the respective kebeles.

\section{REFERENCES}

Abdu A, Tewodros A (2013). Gedeo: Highland Home Garden Agroforestry System. In "Farmers' Strategies for Adapting to and Mitigating Climate Variability and Change through Agroforestry in Ethiopia and Kenya" (C. M. Davis, B. Bernart, and A. Dmitriev, Eds.), pp. 45-50. Forestry Communications Group, Oregon State University, Corvallis, Oregon.

Berhanu M, Getachew W, Derese T (2013). Knowledge and attitude of small holder coffee producing farmers to coffee quality: the case of Oromiya and SNNP regional states. Ethiop. Sky J. Agric. Res. 3(7):98-106

borer, Hypothenemus hampei (Ferrari) (Coleoptera: Scolytidae) on Coffea arabica L. in Ethiopia. Ethiop. J. Biol. Sci. 2:61-72.

Chemeda A, Emana G, Emiru S, Hindorf H, Techale B (2015). Coffee leaf damaging insects' occurrence in the forest coffee ecosystem of southwestern Ethiopia. Afr. J. Plant Sci. 9(2):75-81.

Daniel G (1977). Aspects of climate and water budget in Ethiopia. Addis Ababa University Press, Addis Ababa.

Esayas M, Chemeda A (2007). Preliminay on sources of resistance in COffea arabica L. to coffee leaf miner, Leucoptera caffeina Washbuorn In INter.Confer. Coffee Science, 21 st Montepellier, 1115 Sept.006, ASIC Paris. pp. 1333-1337.

FAO (2010). FAOSTAT database on Agriculture and Nutrition. Food and Agricultural Organization of the United Nations, Rome, Italy. Available at:http://faostat.fao.org/site/569, accessed 12th Aug. 2012.
Fuad AA (2010). Studies on the Diversity of Insect Pests in Wild and Cultivated Coffee Plantations in and Around Jimma, Southwest Ethiopia; Master's thesis at Addis Ababa.

Girma A, Bayetta B, Tesfaye S, Endale T, Taye K (2008). Coffeee Diversity and Knowledge. Addis Ababa, Ethiopia: Ethiopian Institute of Agricultural Research.

GZARD (Gedeo Zone Agriculture and Rural Development) (2015). Annual report (unpublished).

ICO (International Coffee Organization) (2011). Available at: http://www. coffeeclubnetwork.com/redes/form/post?pub_id = 2533). Accessed March 2011.

Jaramillo J, Muchugu E, Vega FE, Davis A, Borgemeister C, ChabiOlaye A (2011). Some like it hot: the influence and implications of climate change on coffee berry borer (Hypothenemus hampei) and coffee production in East Africa. PLoS One 6(9):e24528.

Mendesil E, Jembere B, Seyoum E (2003). Occurrence of coffee berry

Mesfin A (1991). Significance of Ethiopian coffee genetic resources to coffee improvement. In: plant Genetic Resources of Ethiopia (J. M. M. Engels, J. G. Hawkes, and Melaku Worede, Eds.), pp. 354-359.

Million A (1987). Insect pests of coffee with emphasis on Antestia, Antestiopsis intricata in Ethiopia. Int. J. Trop. Insect Sci. 8:977-980.

Million A (2000). Significance of Arthropod pests of coffee in Ethiopia. In "Proceedings of the workshop on the control of Coffeee Berry Disease/CBD in Ethiopia, Addis Ababa, 13-15 Aug. 1999, pp. 67-77.

Moon, RD, Wilson LT (2009). Sampling for detection, IPM decision making. Integrated Pest Management: Concepts, Tactics, Strategies and Case Studies, P 75.

Pedigo LP, Hutchins SH, Higley LG (1986). Economic injury levels in theory and practice. Annual Review of Entomology, 31:341-368.

Pedigo LP, Rice ME (2006). Entomology and Pest Management, 5th edn. Upper Saddle River, NJ: Prentice Hall.

Rechcigl JE, Rechcigl, NA (2000). Insect Pest Management: Techniques for Environmental Protection. LEWIS PUBLISHERS, New York.

Van Der Vossen, HAM (2005). A critical analysis of the agronomic and economic sustainability of organic coffee production. Exp. Agric. 41:449-473.

Waller JM, Bigger M, Hillocks RJ (2007). Coffee Pests, Diseases and Their Management. CAB International, London, UK.

Ward NL, Masters GJ (2007). Linking climate change and species invasion: an illustration using insect herbivores. Glob. Change Biol. 13:1605-1615. 